\title{
Map of Reading and Re-reading: Many Voices, Female Voices, Plath's Voices
}

\author{
Aleksandra Nikčević-Batrićević \\ University of Montenegro, Montenegro \\ Miloš D. Đurić \\ University of Belgrade, Serbia \\ Marija Krivokapić \\ University of Montenegro, Montenegro
}

\begin{abstract}
Pointing towards the variety of possible interpretations of any literary text, we shall briefly explain the focus of feminist readings of the work of Sylvia Plath, with an intention to problematize the way that even this one very specific and challenging corpus of criticism diverges into countless reading avenues. In a chronological context, the critical theory we are observing, i.e. the subject of our interest, belongs to the last three decades of the twentieth and the first decade of the twenty-first century. We shall also demonstrate, by way of illustration, that the lump characterization, proposed by some authors, may hold for the concrete examples which accompany our analysis.
\end{abstract}

Index Terms - interpretation, text, context, American poetry, Sylvia Plath

Certain anthologies, which map the development of literary critical theory during the last decade of the twentieth century, take as a starting point important conclusions while, at the same time, maintaining an analytical focus on all the solutions and perplexities pertinent to this research corpus. The nineties in general, as is obvious from the provided bibliography, ${ }^{1}$ represent an era of reconsideration and, therefore, an era represented by contemporary theoretical cogitation. More precisely, this era is comprised of texts inspired by various factors and authored by figures influential in the domain of the growth of literary critical theory in the last three decades of the twentieth century. These critically conceived volumes have inaugurated a more frequent sprouting of new literary readings and re-readings in connection with a number of relevant issues recurrent within the corpus. While introducing one of these anthologies, Julian Wolfreys maintains, and we strongly consent with him that,

no one single manner of reading will do, so heterogeneous is the world, so diverse are its peoples and cultures, so different are the texts, whether literary, cultural or symbolic by which we tell ourselves and others about ourselves, and by which others speak to us about their differences from us, whether from the present, from some other culture, or from the past, from whatever we may think of as our own culture. (Wolfreys, 1999, p. xii)

While reviewing literary criticism published in the last few decades, such as that authored by Iain Chambers, Susan Sontag or Walter Benjamin, another analogy has lent itself to our observation, and this time it exhibits a cartographic nature. Moreover, this is a supportive analogy, particularly when it comes to the precise mapping of numerous tensions and contradictions that literary scholars face nowadays, and which, at their best, turn into a productive dialogue occupying the spaces of our discernment of the far-reaching changes in literary studies. These are the spaces where senior scholars encounter their junior colleagues. In other words, it is in these mapping loci where representatives of the same generations that have uncompromising attitudes towards the study of text meet. These encounters encode the map function or culture testimony precipitating literary and theoretic registers vis-à-vis the intended literary interpretation. By applying them to this corpus, readers seem to be encouraged, as Kenneth Womack (1999) mentions in his text "Theorising Culture, Reading Ourselves", while looking at the synthesis of social, artistic, political, economic, and linguistic perceptions that have dominated contemporary criticism and the politics of difference defining our recognition of the individual and cultural identity. Furthermore, Womack argues that cultural studies have manifested themselves in a broad range of interpretative dimensions, including a range of research fields, such as gender studies, post-colonialism, race and ethnic studies, pedagogy, eco-criticism, the politics of nationalism, popular culture, postmodernism and historical criticism. Bearing this diversity of interpretative dimensions in mind, it has been increasingly recognized that cultural studies are said to be,

\footnotetext{
${ }^{1}$ Our critical-theoretic approach to Plath's poetry has been informed by the following titles:

Leitch, Vincent A., et al., ed., The Norton Anthology of Theory and Criticism. Second Edition (New York: W.W. Norton and Company, 2010).

Julian Wolfreys, ed., Introducing Literary Theories: A Guide and Glossary (Edinburgh: Edinburgh University Press, 2001).

Julian Wolfreys, Ruth Robbins, and Kenneth Womack. Key Concepts in Literary Theory. Second Edition - Revised and Expanded (Edinburgh:

Edinburgh University Press, 2006).
} 
the international and interdisciplinary phenomenon, the interpretative lens of cultural studies provides us with a means for exploring the cultural codes of a given work, as well as for investigating the institutional, linguistic, historical and sociological forces that inform that's work's publication and critical reception. (Womack, 1999, p. 593)

In one of his papers, also published at the turn of the century, Hillis Miller (1997) asserts that we cannot avoid intertextuality reading at the time of rapidly growing cultural studies, while Womack overwhelmingly supported the premise that critical reading had contributed to the domination of the theory upon entering the twenty-first century. While emphasizing their manifestation within a wide range of interpretative dimensions, Miller chronologically posits them in the rapid transition period of a post-national state. At the same time, explaining miscellaneous segments of contemporary literary theory, including "a wide range of interpretative dimensions", Wolfreys assumes positions similar to Ruth Robbins (1999) ${ }^{2}$. More precisely, by problematizing the singular in this context, he focuses on the concept of 'literary theory', which he sees as problematic, not only because it names the singular object or focus, but because it,

names a single focal point, rather than something composed, constructed or comprised of many aspects or multiple, often quite different identities. If we name several identities or objects as one, not only do we not respect the separateness or singularity of each of those subjects or identities, we also move in some measure toward erasing our comprehension of the difference between those objects and identities, making them in the process invisible. (Wolfreys, 1999, pp. x-xi)

As can be seen from this quotation, Wolfreys' indication is similar to that proposed by Roland Barthes who, according to K. M. Newton (1999), was a critic never standing still, and whose various work phases can be approached from a variety of perspectives, making him difficult to "locate" and classify. Nonetheless, as Newton further perceives, the structuralism of Barthes is closely connected to his being fond of modernism, his interest in the politics of writing and reading, his rejection of the division between art and criticism, but also with his awareness of the post-structuralist achievements. Consequently, the burden of locating and classifying reappears in literary theory through constant probes and queries, writes Newton, while Montenegrin scholar Marjana Đukić points to this specific event in theory by stating how the answers pass away while the questions remain: the answers are always interrogated anew, while the questions are summoned repeatedly.

In a similar manner, apart from arguing against the justifiability of the capitalist enactment in its various appearances, Marxist criticism asserts that there is a strong bond between word and world, theory and practice ${ }^{3}$ (1999, pp. 99-109). At the same time, according to Wolfreys, deconstruction announces reforms and is, therefore, imminent to the conceptual languages of the Western metaphysics, which really, as Derrida argued, has unavoidable inner effects (1999, pp. 267-282). Similarly, the psychoanalytical approach to literature combines the methods that literary theory uses in describing texts with the psychoanalytical methods of approaching uncanny verbalizations and treating them as a source of information from the unconscious mind of the speaker for therapeutic reasons ${ }^{4}$ (1999, pp. 201-211). John Brannigan (1999, pp. 417-428), on the other hand, understands that literature and history cannot be separated and that history is not understood as a coherent compilation of objective knowledge that can be simply applied to a literary text with the intention of discovering what the text is supposed to reflect or not reflect. According to new historicists, literature reveals processes and tensions leading to historical changes, although it never remains in a passive relationship towards history: on the contrary, as Brannigan writes - literature models and constitutes historic change, literary texts influence historical flows, as well as social and political ideas and the beliefs of the times during which they are being produced, thus not seeing a text or its context as its sole subject of research, as not only does literary history constitute its main interest, but it is rather literature in history. This means that it perceives literature as an inseparable part of history in the process of its development and as being pregnant with creative and deconstructive powers, and together with all the contradictions of history. (1999, pp. 417-428) Furthermore, as we read in Brannigan's text, the role of historical contexts in the process of interpreting text and the role of literary rhetoric in the process of intermediating history are among the most crucial issues that critics coming from this theoretical corpus are dealing with. Still, discussing the reader-response theory in the aforementioned anthology, Martin McQuillan maintains that regardless of whether one studies literature or is a literary critic, one must above everything else be a reader. For that reason, he goes on to elaborate, if literary theory insists on denying the assumptions about the importance of the personal experience of a work of literature, it would be correct then that it reinvestigates what naturally belongs to literature and that is the very process of reading. Without reading and readers, he concludes, literature would not be. (1999, p. 139, pp. 139-149)

When it comes to feminist criticism in particular, we shall look at the opus of Sylvia Plath in order to show that even that one school of criticism must depart from its interpretative centre and arrive at diverse and sometimes opposing interpretative avenues, never capable of avoiding any of the schools mentioned above. Thus, in her text about feminism

\footnotetext{
${ }^{2}$ Ruth Robbins, among others, takes an affirmative position towards the existence of literary feminisms. Her paper is published in Wolfreys' anthology, published in 1999.

${ }^{3}$ See, for example, the following authors:

Terry Eagleton, Marxism and Literary Criticism (London and New York: Routledge, 1976).

Fredric Jameson, Marxism and Form: Twentieth-Century Dialectical Theories of Literature (Princeton: Princeton University Press, 1971).

Raymond Williams, Marxism and Literature (Oxford: Oxford University Press, 1977).

${ }^{4}$ See, for example, the following authors:

Maud Ellmann, ed., Psychoanalytic Literary Criticism (London: Longman, 1994).

Anthony Elliott, Psychoanalytic Theory: An Introduction (Oxford: Blackwell, 1994).
} 
in critical theory and its efforts to contribute against the dominance of the patriarchal social structures, Ruth Robbins (Wolfreys, 1999, pp. 49-59) draws attention precisely to the improbability of levelling feminism to a singular discipline. It is essential, she believes, for the third wave or the post-feminist chronological framework, to bring the use of the plural form as regular - beginning with the very term 'feminisms' into all the other aspects of theory, which is compliant with the contemporary situation of critical theory in general. This is because "it is not a unified theory with a single corpus of work that has to be read before you can begin: there is no feminist Marx or Freud whose oeuvre defines feminism as theory and methodology. This fact is the strength and the frustration of feminism." (1999, p. 49) According to Robbins, feminist theory is best understood if it is defined as an incessant series of interventions within the reading practice, which develops specific politics of reading and presupposes that reading practice can transform the way we experience the world. She identifies feminist theory as being based on the existence of relations between the text and the world. In addition to this, she points out the relationship between the texts and the worlds as being primarily political because they deal with the question of power, as will be exemplified further in the text, in the case of Sylvia Plath, whose work constantly overlaps with her status in the culture, "or between her own status in the culture and the cultural phenomena of which she writes", remaining aesthetic, sexual and cultural-political in scope (Rose, 1992, p. 8, p. 24). After this, the attention is shifted to the position of the woman author, which Robbins defines as significant for a number of practical reasons (education, publishers, reviewers, writing spaces, language):

The project of rediscovery was inaugurated to find the women writers who had become hidden from literary history, to republish their works, to edit them in scholarly editions and to make a female tradition of literature to set beside the so-called 'great' tradition of great men. (1999, p. 52)

With the ambition of preparing the reader for the portentous aptitude of literary theory registers, we have emphasized their intertwinement with histories, languages, and cultures, as well as their underlying global tendencies and local specifics. Imminent to this register is a tendency, typical of intellectual concepts in general, to keep hold of a position of dependence and stability. Although these fixed referents and measures have become the main agents when maps are brought to our attention, there are also unavoidable fluctuations as well as changeability in considerations of literary reality ${ }^{5}$. The best introduction to this branching story, which at moments, seems to lose its awareness of its roots, we find in Feminisms: An Anthology of Literary Theory and Criticism edited by Warhol and Herndl (1997).

The concept of Feminisms, based as it is upon multiplicity, depends, as we have said, upon accepting heterogeneity within feminist literary studies. This does not mean that we, as editors, position ourselves as "pluralists", or as theorists who think that "anything goes". As independent critics, each of us agrees with some of the pieces in this collection, and each disapproves of others. [...] We do always believe that each essay here represents a viable - and important - voice in contemporary feminist literary studies, one that should be heard. Still we recognize that the diversity of views represented here sometimes leads to irreconcilable logical conflicts. There is no way to force these many voices into a unison performance, or even - in some cases - to make them harmonize. (1997, p. xii)

The impossibility of reducing this story to a monologue resulted also from an attempt at synthesizing the reactions to various phases in the development of feminist critical theory, such as concentrating on a woman as a writer, writes Robbins: however, this is prone to glamorizing textuality, gynocriticism that risked essentialism, to which Toril Moi devoted some pages (Wolfreys, 1999, p. 52). Besides, third-wave feminism finds the question of interdisciplinarity of special interest, as it focuses on alternatives to issues that were previously the focus of feminist scholarship, thereby strengthening its methodological reach and concentrating beyond the implications of the first- and second-wave problematic, with each term questioning the other. This kind of knowledge production acquires the structure of a patchwork, which presents one of the possible paths that feminist philosophy could take, as emphasized by Stella Sandford (2002, pp. 139-160), whose focus on Levinas has attracted diverse feminist perspectives. Sandford confirms that one of the reasons for the pull of this depth is historical coincidence, according to the interest that philosophy has displayed in the work of Levinas and bearing in mind that it strikingly blossomed in the late eighties and the early nineties thus coinciding with the optimization of "feminist philosophy". Feminist interest, too, includes other aspects of Levinas's work, such as the role and the nature of the concept of the "feminine", as well as major issues of feminist controversies brought with the said concept - ranging from the unreservedly affirmative to the absolutely rejective, but that one must also have in mind the fact that, in turn, Levinas's position has also changed in the context of feminist reading, as Sandford emphasizes (Bernasconi, 2002)

In the third wave of feminist criticism, reflections on body, sexuality, and gender are considered closely related entities. Moreover, all concepts are perceived as transgressing with regard to a particularly contested third-wave space, when several variants of feminism developed, as perceived in the essays published at the turn of the century that deal with paradigms such as the body and "writing the body" presenting the body as a cultural medium" . (2010, pp. 22402245) The body, as anthropologist Mary Douglas says (2010), as a powerful symbolic form, defines a surface ruled by what is essential, which is the hierarchies of a culture, while, even the culture's metaphysical vows, are written upon it

\footnotetext{
${ }^{5}$ In this context, Ian Chambers's text titled "Cities Without Maps" has been useful to us. (1999, pp. 611-626)

${ }^{6}$ For example, see:

Ann Rosalind Jones, "Writing the Body: Toward and Understanding of L'Écriture Féminine," in Feminisms, ed. Robyn R. Warhol and Diane Price Herndl (New Brunswick: Rutgers University Press, 1997), pp. 370-383.

Rosemarie Tong, Feminist Thought: A Comprehensive Introduction (New York: Routledge, 1997).
} 
and thus toughened by particular bodily language. This conception also dates back to very early texts, such as one from 1913 entitled "Why I Wrote The Yellow Wallpaper", by Charlotte Perkins Gilman (2007), in which the author writes how "for many years [she] suffered from a severe and continuous nervous breakdown tending to melancholia and beyond." During the third year of this problematic and troublesome time the author went,

in devout faith and some faint stir of hope, to a noted specialist in nervous diseases, the best known in the country. This wise man put me to bed and applied the rest cure, to which a still-good physique responded so promptly that he concluded there was nothing much the matter with me, and sent me home with solemn advice to "live as domestic a life as far as possible," to "have but two hours' intellectual life a day" and "never to touch pen, brush, or pencil again"” as long as I live. (2007, p. 119)

Sylvia Plath's poetry was widely interpreted in the decades following her death, and those readings were under the huge influence of the aforementioned interpretative models. For the purpose of this paper and the obvious lack of space, we will work with the three pivotal studies, which are listed in the text that follows, as it is Revising Life: Sylvia Plath's Ariel Poems (1993), in which Susan R. Van Dyne maps the fifties and the sixties as a period of significance in Plath's life history ${ }^{8}$ and emphasizes two major objectives that remained emblemetized: to become a perfect mother and a renowned poet, despite the cultural myths that define feminine self-expression as most perfectly realized within the first domain. Likewise, the early feminist reading of Plath's work logically strongly supported these endeavours. This, for many, predominant theme of Plath's poetry has never been overlooked or denied after the first postulated wave of interpretations, but was enriched, as we pointed out at the beginning, by continuous reinterpretations. In the poetry written after the birth of her children, as Van Dyne explains, Plath had to revise the purpose she had set at the beginning and this new literary venture was identified as the central metaphor of her work by the new wave of feminist critics. Unrelenting questions started forcing themselves into the lyrical vision of the poet: do motherhood and writing stand in a harmonious or conflicting relationship? is the metaphor analogous to motherhood? does it stand in an ambivalent defence against it? (1993, p. 144) Van Dyne observes that for Plath motherhood was not a stable, unified, or a transparent category and what it may have meant had to be incessantly re-modified. Likewise, a study by Jacqueline Rose (1991) makes a shift into feminist reading revealing new semantic arches of Plath's texts. Her The Haunting of Sylvia Plath provoked the most ardent reaction in Ted Hughes, as it talks about Hughes' role in Plath's life and in his editing of her collection of Ariel poems, while he is presented as silencing her, transforming her voice so as to suit his own interests, Rose writes, further emphasizing: "In my reading, Plath regularly unsettles certainties of language, identity and sexuality, troubling the forms of cohesion on which 'civilised' culture systematically and often oppressively relies. My suggestion that this might be the case, specifically in the field of sexuality, has provoked the strongest reactions from the estate. The question then arises - who is to decide the limits of unacceptable? Who is to decide what it is acceptable for the unacceptable to be?" (1991, p. xii)

In his mapping of Plath's unsettling of "certainties of language, identity and sexuality", Butscher (2003) acknowledges that the Ariel poems contain means by which Plath rid herself of the poison that had been her bane for years and explains how the poems served as a catharsis for repressed feelings. This poetry collection, he claims, grew into a perfect metaphor for the newly freed being and for the art it was about to institute, the art that is both desperate and exciting, surprisingly finding its true expression in the masculine will to power. For Van Dyne the whole collection presents Plath as an impertinent voice directing its poetics through a passionate transubstantiation of the female subject, while the creative freedom is highlighted through the figures that are symbolically carnal and transgressively sexual. According to Rose, who explains how Plath was constituted as a literary subject on the battlefield of cultural survival, "Lady Lazarus" most frequently locates Plath's transcendental femininity, alluding to the origin of myth and recapitulating the cyclical scheme of dying and regeneration. Not being the only critic who have perceived the correspondence between Plath's speakers and her personal crisis, Alvarez has depicted his fascination with the objectivity with which the poet treats personal material: not only does she write about her personal worries, but she brings closer the locality and vicinity of pain.

In her highly subtle elaboration of the poem, Linda K. Bundtzen defines "Lady Lazarus" as "an allegory about the woman artist's struggle for autonomy": "The female creature of a male artist-god is asserting independent creative powers. Next to Lady Lazarus's miraculous rise at the end, the male god's art is an inept engineering feat. Where at the beginning of the poem the Lady merely manifests his potency - indeed, postulating her imagination by playing the role of female exhibitionist - by the end of the poem she is a creator in her own power" (2001, pp. 86-87). For Christina Britzolakis, Plath's rhetoric, foregrounding in that way questions of sexuality and power, can be read as encoding a spectacular relation between poet and audience: “As 'Lady Lazarus' demonstrates, the ironic secularity at work in Plath's language is an effect not merely of literary history, or of a gendered literary market, but also of a culture of consumption in which images of women circulate as commodities. Among the personae which appear most frequently in Plath's poetry are those of the prostitute, the female performer and the mechanical woman. In 'Fever 103', as in 'Lady Lazarus', the speaker occupies all three of these roles, oscillating between the positions of artist and artefact,

\footnotetext{
${ }^{7}$ See also:

Helen Lefkowitz Horowitz, Wild Unrest: Charlotte Perkins Gilman and the Making of "The Yellow Wall-Paper" (Oxford: Oxford University Press, 2010).

${ }^{8}$ Susan R. Van Dyne, Revising Life: Sylvia Plath's Ariel Poems (Chapel Hill: University of North Carolina Press, 1993).
} 
consumer and commodity-spectacle. Indeed, Ariel situates itself as part of a culture in which self-revelation or selfexpression has itself become a cliché: what 'Lady Lazarus' calls 'the big strip tease'.” (2006, pp. 114-115)

Reading Plath's poems against the background of contemporary history and politics continues to be a popular practice, as we perceive in the most recent books devoted to the exploration of "many layers of her often unreliable and complex representations and the difficult relationship between the reader and the text" (Bayley, Brain, 2011), while also evaluating "the historical, familial and cultural sources that Plath drew upon for material: from family photographs, letters and personal history to contemporary literary and cinematic Holocaust texts" (2011, p. i), offering "no singular form or vision" (Rose, p. 4), but utterances that are different, "each one contradicting as much as completing the others, each on no less true for the disparity which relates them and sets them apart (Rose, pp. 4-5). These pointers defined by Rose as always talking about "the implication of the psyche in history, and of history within the psyche", are clearly stated in Plath's "Context" (2007, pp. 167-169), in which she defines her poems as deflections, not as an escape: "For me, the real issues of our time are the issues of every time - the hurt and wonder of loving; making in all its forms children, loaves of bread, painting, buildings; and the conservation of life of all people in all places, the jeopardizing of which no abstract doubletalk of 'peace' or 'implacable foes' can excuse.” (2007, p. 169) Rose (1991) points out that Plath was often criticized because of the way she intertwined her personal mythology with events of historic significance, especially with fascism and the Holocaust, and that she was condemned for trivializing history and aggrandizing her own being, transforming real terror into fantasy, using the terror as a metaphor for searching into and revealing for the outside world her own being. In addition, Alvarez (1971) perceives that this is precisely the relevant element in her work mainly due to different reasons, while poetry and death remain inseparable: "The one could not exist without the other. And this is right. In a curious way, the poems read as though they were written posthumously."

We have not, of course, depleted the possibilities of meanings within Plath's work, neither was it our aim, but we were hoping to prove not only that they are inexhaustible but also that each advancing fashion of critical discourse modified what Foucault defined as the author-function, hence inaugurating significant (although often not too obvious) cultural changes. With their textual references and indications, the books from which we have quoted and paraphrased in this text, help us fixate the flow of time in its mosaic structure of political, economical, and cultural relapses, as they equally look back at the opposition of centre/core and the periphery/margin. Thus, they introduce us to the analysis of contemporary critical thinking and offer us a better understanding of the present. As Fredrick Jameson once said, they will invoke in us nostalgia for the present and a desire to approach it in an urgent manner in order to leave valuable textual traces behind us. Finally, their pages will also inspire us to dream of the future, which most probably will be defined by subversion and innovation, but also by more formal approaches displaying extravagant idiosyncrasies of the new, because sometimes new threats are transformed into banal and trivial ones.

\section{REFERENCES}

[1] Alvarez, Al. (1971). The Savage God: A Study of Suicide. London: Weidenfeld\&Nicolson.

[2] Bayley, Sally, Tracy Brain, eds. (2011). Representing Sylvia Plath. Cambridge: Cambridge University Press.

[3] Bloom, Harold, ed. (2002). Sylvia Plath: Comprehensive Search and Study Guide. Philadelphia: Chelsea House Publishing.

[4] Butscher, Edward. (2003). Sylvia Plath: Method and Madness. Tuscon, Arizona: Schaffner Press.

[5] Critchley S., R. Bernasconi, eds. (2002). The Cambridge Companion to Levinas. Cambridge: Cambridge University Press.

[6] Eagleton, Terry. (1976). Marxism and Literary Criticism. London and New York: Routledge.

[7] Elliott, Anthony. (1994). Psychoanalytic Theory: An Introduction. Oxford: Blackwell.

[8] Ellmann, Maud, ed. (1994). Psychoanalytic Literary Criticism. London: Longman.

[9] Gilbert, Sandra M., Susan Gubar eds. (2007). Feminist Literary Theory and Criticism: A Norton Reader. New York: W. W. Norton \& Company.

[10] Gill, Jo, ed. (2006). The Cambridge Companion to Sylvia Plath. Cambridge: Cambridge University Press.

[11] Hillis Miller, J. (1990). Tropes, Parables, Performatives: Essays on Twentieth Century Literature. Duke: Duke University Press.

[12] Hillis Miller, J. (1991). Theory Now and Then. Duke: Duke University Press.

[13] Jameson, Frederic. (1971). Marxism and Form: Twentieth-Century Dialectical Theories of Literature. Princeton: Princeton University Press.

[14] Jones, Ann Rosalind. (1997). “Writing the Body: Toward and Understanding of L’Écriture Féminine.” In Feminisms, eds. Robyn R. Warhol and Diane Price Herndl. New Brunswick: Rutgers University Press.

[15] Lefkowitz Horowitz, Helen. (2010). Wild Unrest: Charlotte Perkins Gilman and the Making of "The Yellow Wall-Paper". Oxford: Oxford University Press.

[16] Leitch, Vincent E. et al., ed. (2010). The Norton Anthology of Theory and Criticism. New York: W.W. Norton and Company.

[17] Moi, Toril. (2002). Sexual/Textual Politics: Feminist Literary Theory. London and New York: Routledge.

[18] Robbins, Ruth. (2000). Literary Feminisms. New York: Palgrave Macmillan.

[19] Rose, Jacqueline. (1992). The Haunting of Sylvia Plath. Cambridge: Harvard University Press.

[20] Tong, Rosemarie. (1997). Feminist Thought: A Comprehensive Introduction. New York: Routledge.

[21] Van Dyne, Susan R. (1993). Revising Life: Sylvia Plath's Ariel Poems. Chapel Hill: University of North Carolina Press.

[22] Warhol, Robyn V. and Diane Price Herndl, eds. (1997). Feminisms: An Anthology of Literary Theory and Criticism. New Brunswick: Rutgers University Press.

[23] Williams, Raymond. (1977). Marxism and Literature. Oxford: Oxford University Press.

[24] Wolfreys, Julian, ed. (1999). Literary Theories: A Reader and A Guide. New York: New York University Press.

[25] Wolfreys, Julian, ed. (2001). Introducing Literary Theories: A Guide and Glossary. Edinburgh: Edinburgh University Press. 
[26] Wolfreys, Julian, Ruth Robbins, and Kenneth Womack, eds. (2006). Key Concepts in Literary Theory. Edinburgh: Edinburgh University Press.

[27] Womack, Kenneth, ed. (2008). Books and Beyond: The Greenwood Encyclopedia of New American Reading. Volume 1, 2, 3 , and 4. Westport, Connecticut: Greenwood Press.

Aleksandra Nikčević-Batrićević teaches courses on American literature, American women poetry and feminist literary theory and criticism at the University of Montenegro (Faculty of Philosophy, Department of English Language and Literature). Her M.A. and $\mathrm{Ph} . \mathrm{D}$ are in American literature. Her publications include papers on Sylvia Plath, Anne Sexton, second wave feminism, Herman Melville and other American authors.

Miloš D. Đurić has been teaching English for Electrical Engineering and English for Software Engineering, respectively, for more than a decade at the Faculty of Electrical Engineering, University of Belgrade, where he is currently a Senior Lecturer and Chair of the Department of General Education. He is also a Visiting Senior Lecturer at the Faculty of Mechanical Engineering in Belgrade. Additionally, he was a Visiting Senior Lecturer at the Faculty of Medicine in Belgrade. His scientific research is focussed on: English for Electrical Engineering, English for Software Engineering, English for Mechanical Engineering, English for Academic Medical Purposes and Theory of Translation.

Marija Krivokapić teaches 19th- and 20th century British Literature at the Faculty of Philosophy, University of Montenegro. Her publications focus on the work on D. H. Lawrence, but her recent interest also include contemporary Native American literature, and travel writing. 